\title{
Correction to: Assessment of the dunnocks' introduction to New Zealand using innate immune-gene diversity
}

\author{
Carlos E. Lara ${ }^{1,2}$ (D) . Catherine E. Grueber ${ }^{3} \cdot$ Benedikt Holtmann $^{4}$. \\ Eduardo S. A. Santos ${ }^{5}$. Sheri L. Johnson ${ }^{1}$ - Bruce C. Robertson ${ }^{1}$. \\ Gabriel J. Castaño-Villa ${ }^{2,6} \cdot$ Malgorzata Lagisz $^{7} \cdot$ Shinichi Nakagawa ${ }^{7}$
}

Published online: 11 February 2021

(c) Springer Nature Switzerland AG 2021

\section{Correction to: Evolutionary Ecology (2020) 34:803-820 https://doi.org/10.1007/s10682-020-10070-0}

In the original publication of the article Evol Ecol 34, 803-820 (2020) we suggested that "Historical records from the Otago Acclimatisation Society indicate that in the Otago region... a total of 185 individuals...were introduced from United Kingdom between 1865 and 1907 (Santos 2012; Santos and Nakagawa 2013)". However, after reviewing Duncan (1997) and reading Pipek et al. (2015), it seems more plausible that only 98 individuals were introduced in 1868. Notably, this correction does not affect our results. On the contrary, it makes our main finding stronger (i.e., even fewer individuals than thought originally, were enough to bring all the genetic diversity from England to New Zealand). Also note that the time of isolation proposed between the two populations is not affected by this correction. It is because $2017-1868=149$ years, which is $c a$. 150 years.

The original article can be found online at https://doi.org/10.1007/s10682-020-10070-0.

Carlos E. Lara

celarav@gmail.com

1 Department of Zoology, University of Otago, Dunedin, New Zealand

2 Grupo de Investigación GEBIOME, Facultad de Ciencias Exactas Y Naturales, Universidad de Caldas, Manizales, Colombia

3 School of Life and Environmental Sciences, Faculty of Science, The University of Sydney, Sydney, NSW, Australia

4 Behavioural Ecology, Department of Biology, Ludwig-Maximilians-University of Munich, Großhaderner Straße 2, 82152 Planegg-Martinsried, Germany

5 Departamento de Zoologia, Instituto de Biociências, Universidade de São Paulo, São Paulo, Brazil

6 Departamento de Desarrollo Rural Y Recursos Naturales, Universidad de Caldas, Manizales, Colombia

7 Evolution and Ecology Research Centre, School of Biological, Earth and Environmental Sciences, University of New South, Sydney, NSW, Australia 


\section{References}

Duncan RP (1997) The role of competition and introduction effort in the success of passeriform birds introduced to New Zealand. Am Nat 149:903-915

Pipek P, Pyšek P, Blackburn TM (2015) A clarification of the origins of birds released by the Otago Acclimatisation Society from 1876 to 1882 . Notornis 62:105-112

Santos ESA (2012) Discovery of previously unknown historical records on the introduction of dunnocks (Prunella modularis) into Otago, New Zealand during the 19th century. Notornis 59:79-81

Santos E, Nakagawa S (2013) Breeding biology and variable mating system of a population of introduced dunnocks (Prunella modularis) in New Zealand. PLoS ONE 8:e69329

Publisher's Note Springer Nature remains neutral with regard to jurisdictional claims in published maps and institutional affiliations. 